\title{
América Latina-EJA
}
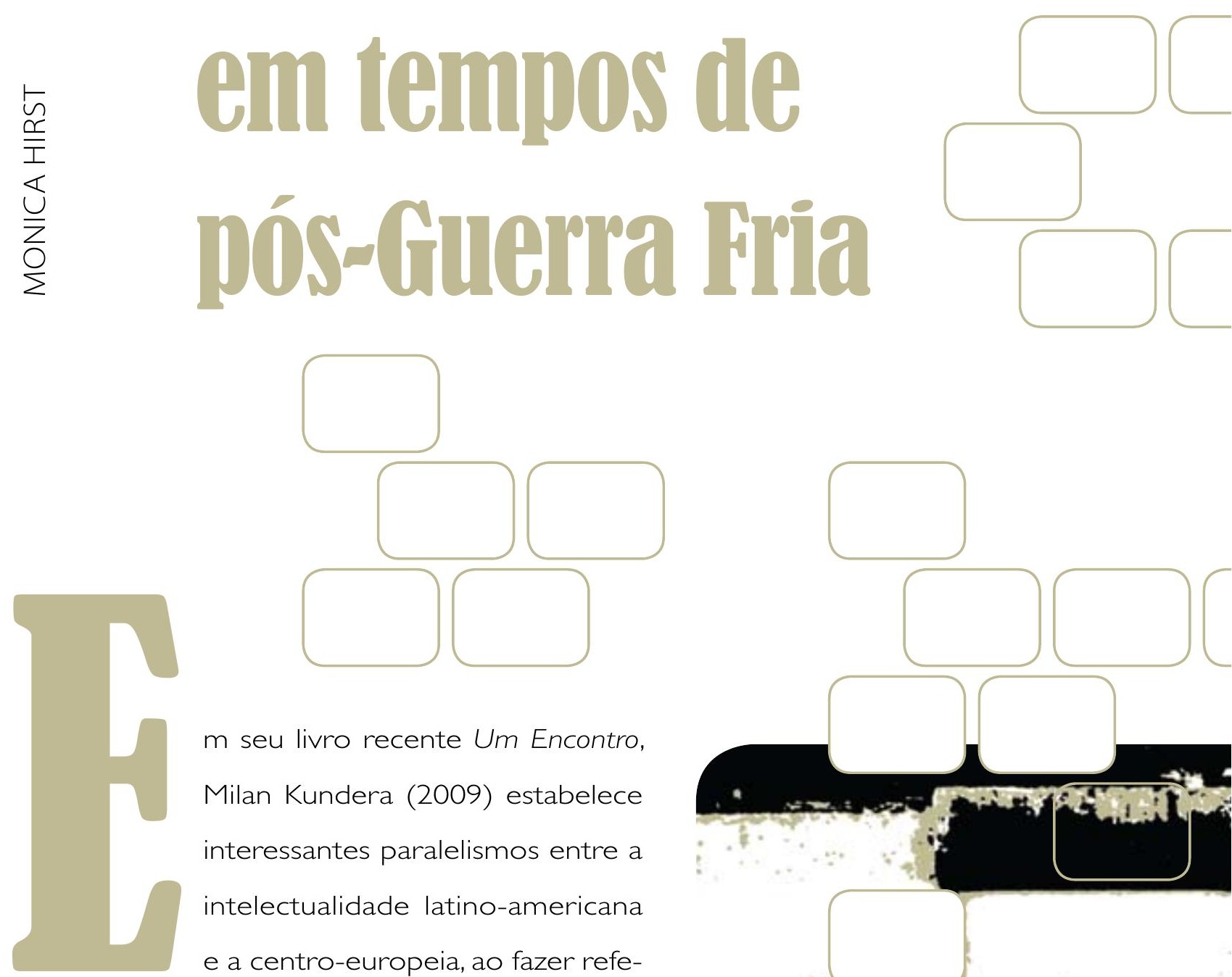

$m$ seu livro recente Um Encontro, Milan Kundera (2009) estabelece interessantes paralelismos entre a intelectualidade latino-americana e a centro-europeia, ao fazer refe-

rência aos laços de solidariedade antiautoritários mantidos durante os anos da Guerra Fria. Robert Skidelsky (1995), na obra The World After Communism, fez algo parecido no campo da economia política quando sugeriu uma articulação entre os desmantelamentos das economias planificadas da Europa oriental e dos modelos substitutivos na América Latina. No terreno das políticas comparadas, Adam Przeworski (1991) - entre outros - explorou nos anos 90 as coincidências e diferenças entre os processos de transição de-

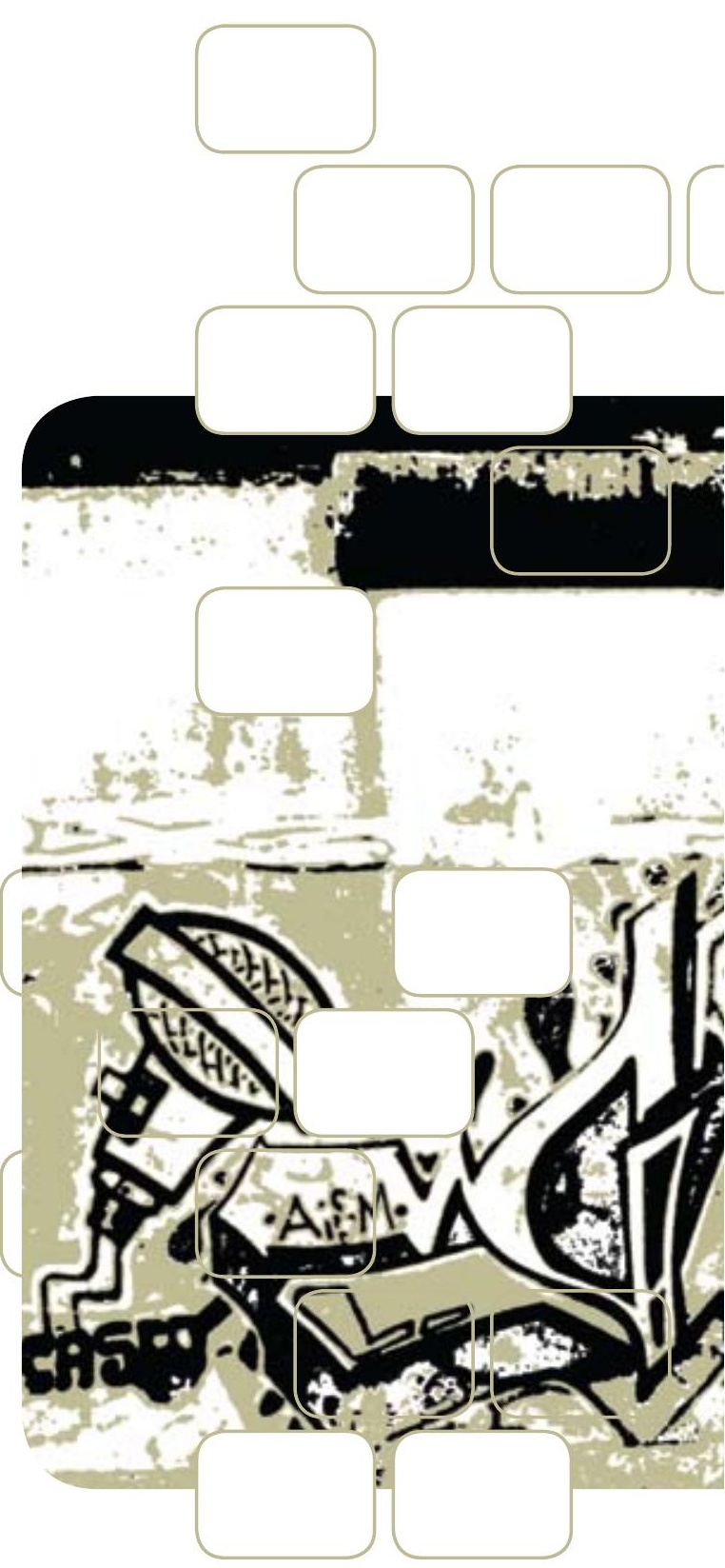


MONICA HIRST

é professora de

Política Internacional

da Universidade

Torcuato di Tella

(Buenos Aires).
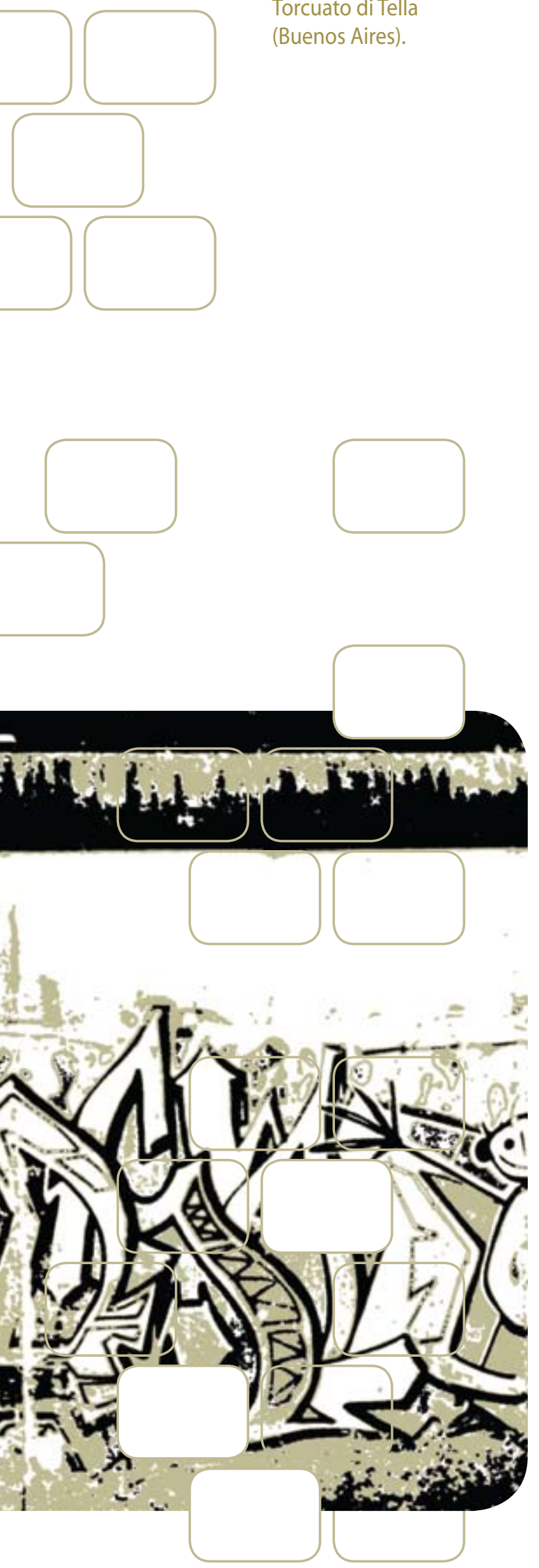

mocrática experimentados nos dois contextos sub-regionais.

Não se conhece, entretanto,uma abordagem desse tipo aplicada à política internacional, na qual se compare a desarticulação das duas regiões como áreas de influência das superpotências responsáveis pela configuração do sistema mundial durante 45 anos de conflito leste-oeste. Talvez uma razão para essa lacuna sejam os ritmos e os momentos diferentes de ambos os processos. Enquanto os países-satélites da URSS se livraram de sua condição subordinada de forma simultânea à caída do Muro de Berlim, a América Latina manteve-se como área de influência por vários anos após o esgotamento da bipolaridade mundial.

A desarticulação desse "enquadramento" se deu lentamente, primeiramente com uma diferenciação entre o norte e o sul da região quanto ao padrão de relacionamento com os EUA e, posteriormente, como uma consequência colateral da sobre-extensão imperial norteamericana a partir do II de Setembro. Neste artigo se procurará oferecer uma breve análise de ambos os momentos.

\section{LENTO DESMANTELAMENTO DE UMA ÁREA DEE INFLUÊNCCIA}

Vem se tornando frequente que analistas internacionais de renome incluam a qualidade do relacionamento de Washington com os países 


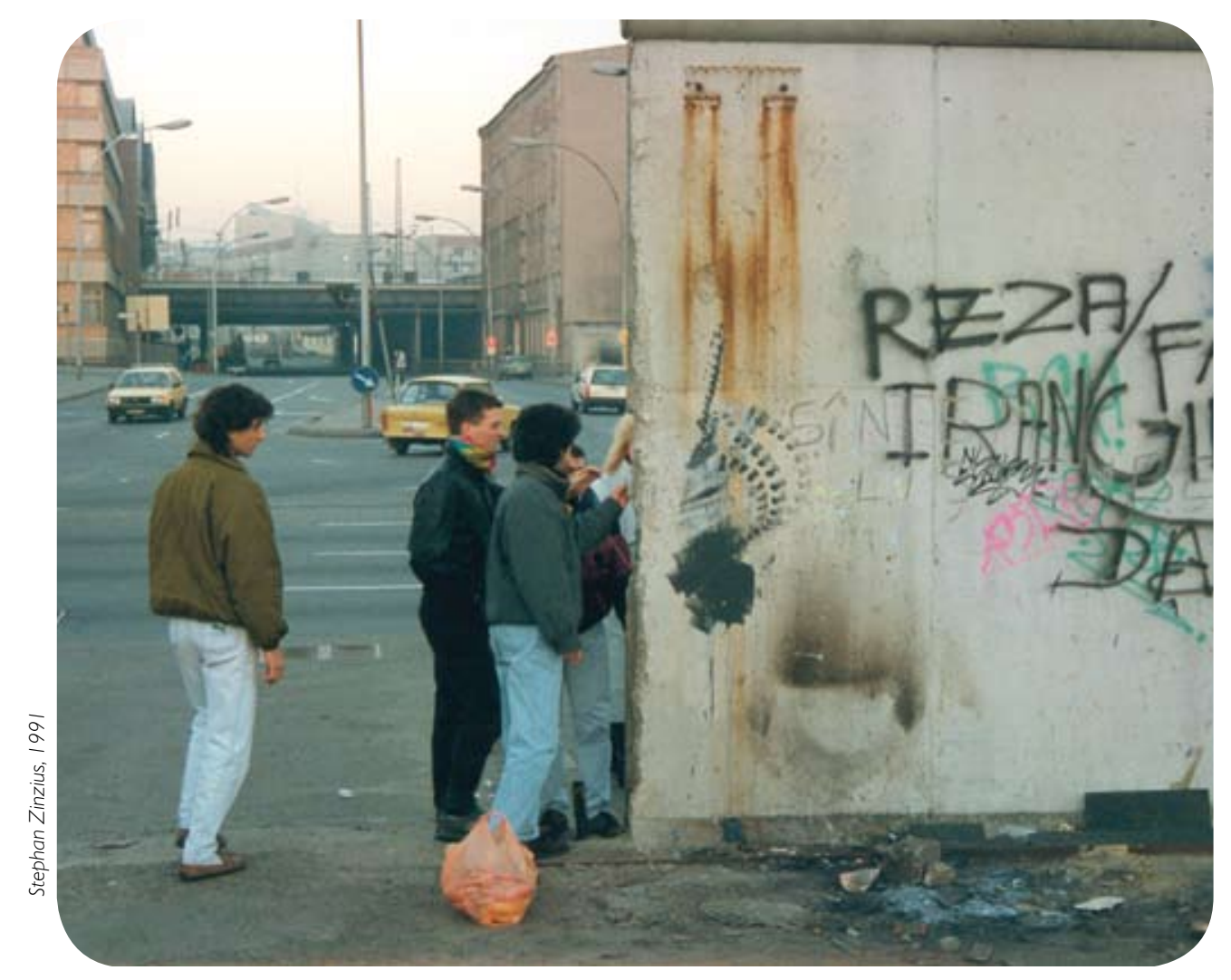

latino-americanos como um dos indicadores de falência do projeto imperial norte-americano. Autores como Joseph Nye e Stanley Hoffman, que, no passado, raramente mencionavam nossa região, passaram a sublinhar o desdém da administração Bush com a área como um sinal de perda de rumo da política externa dos Estados Unidos após o 11 de Setembro. Indica-se a "insubordinação" dos governos da América Latina, e particularmente da América do Sul, como um sinal de uma crise de liderança que revelou o mau uso de recursos de poder em nome de prioridades estratégicas equivocadas. Ganhou força a aplicação do conceito de sobre-extensão imperial para explicar esse processo, considerando-se que os EUA passaram a privilegiar de forma exagerada políticas estratégicas que se apoiavam em seu poderio militar ${ }^{1}$.

Haveria, dessa forma, uma relação entre o desmantelamento da única área de influência sobrevivente após a queda o Muro de Berlim e o momentum da política externa norte-americana a partir de 2001. Tratar-se- ia de um processo de tensões ocasionado pela quebra do poder hegemônico dos EUA junto aos estados latino-americanos, no qual a fragmentação se sobrepôs à cooperação entre as partes. Poder-se-ia identificar um movimento de esgotamento de uma agenda positiva que, se bem que sempre esteve sujeita a marcadas assimetrias, constituiu um fator de estabilidade no âmbito americano desde os anos 40 do século passado. Diferentemente de outros momentos, é possível observar uma dinâmica na qual a região perdera sua funcionalidade para o projeto de poder dos Estados Unidos. Assim, a incapacidade dos Estados Unidos de preservarem sua ascendência se sublinharia, apesar da ausência de ameaças e/ou competidores extrarregionais.

A literatura que aborda específica ou genericamente o relacionamento interamericano como parte de um projeto de poder de amplo alcance coincide em dois pontos: o primeiro, que sua preeminência sobre a região, apesar de haver passado por variações, está inspirada e fundamentada extensão imperial ver: Sny der, $|99|$. 
pela Doutrina Monroe; o segundo, que em raros momentos esta deixou de estar marcada por uma postura negligente vis$\grave{a}$-vis a comunidade latino-americana ${ }^{2}$. A caracterização da América Latina como uma esfera de influência, que em diversas ocasiões guardou semelhança com a de uma zona colonial, informal que precede a Guerra Fria e se preserva após sua finalização, também constitui um argumento recorrente, o que reforça a sua condição de subordinação estratégica, "quintal traseiro" e área de repetidas intervenções.

Do ponto de vista estrutural, o relacionamento dos EUA com os países da região esteve pautado por marcadas assimetrias e um isolamento relativo de outros contextos externos, reforçado por três fatores: a) o poder coercitivo dos interesses norte-americanos na região; b) a limitada capacidade de articulação coletiva de políticas defensivas entre os países da área; e c) o papel estabilizador exercido pelos Estados Unidos em situações de conflitos intra e interestatais. $O$ fato de que a presença dominante de Washington pôde manter-se por mais de 60 anos a custos relativos baixos, graças em grande medida à irrelevância estratégica latino-americana, explica o conteúdo negligente, inconsistente e errático da política aplicada na região.

O costume de intervir significou uma relativização de facto da soberania dos estados da região, tratando-se de um direito autoassegurado, livremente exercido pelas sucessivas administrações norte-americanas após a fase de imperialismo colonialista dos primeiros anos do século $\mathrm{XX}^{3}$. Impõe-se aqui o atual debate sobre o modelo de império a ser aplicado aos Estados Unidos, qual o seu grau de excepcionalidade e como se diferencia a ideia do uso de um poder imperial que tornava legítima a intervenção e fazia dessa mesma um exercício benevolente de autoridade e responsabilidade. Em qualquer caso, a identificação dessa política com uma projeção hegemônica tornou-se o viés explicativo mais indicado para o tipo de interação estabelecido entre Washington e os países latino-americanos a partir dos anos 30. Ao longo dos 45 anos do conflito leste-oeste, apesar de marginal, a América Latina foi parte ativa do conjunto de organismos multilaterais que outorgaram uma faceta institucional à liderança dos Estados Unidos, assegurando-lhe sustentação e legitimidade. A instituição do Sistema Interamericano conferiu um âmbito específico para que o hegemon exercesse - em bases consensuais e pouco conflitivas - sua autoridade, apoiado por um conjunto de estados mais fracos - com o qual compartilhava a identidade americana.

Mas o poder de intervenção dos Estados Unidos na América do Sul reduziu-se notavelmente na etapa final da Guerra Fria, em função do desaparecimento da convergência ideológica construída nos anos dourados do conflito leste-oeste. Não obstante, o império conservou sua capacidade coercitiva exercida através de seu poder de pressão e de agenda, logrando gerar uma ilusão de comunhão de interesses na primeira década do pós-Guerra Fria.

Nos anos 90 os Estados Unidos contribuíram para aprofundar a especificidade sulamericana no contexto latino-americano, estimulando uma diferenciação baseada em preferências econômico-comerciais que posteriormente passaram a se projetar em temas de segurança. Após a formação de uma área de livre-comércio com o México e o Canadá, em 1994, foi instituído um regime de preferências com os países do Caribe e a América Central (2005) e a formação do Comando Norte (2002). À fragmentação entre o norte e o sul da América Latina, somou-se o impacto causado pela securitização da agenda hemisférica a partir do 11 de Setembro.

Estabelecer-se-ia, a partir de então, uma diferença entre o que se considera uma zona de segurança, que cobre os territórios do México, América Central e Caribe, e a preservação de uma área de influência que abarca a América do Sul, com exceção da Colômbia, cuja vinculação estratégica com Washington segue o padrão do primeiro modelo(Hirst, 2003). Os países que integravam a zona de segurança já não dispunham de autonomia uma vez que suas respectivas políticas de defesa obedeciam, em sua

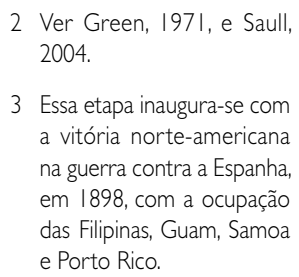


totalidade, às premissas estratégicas norteamericanas. As ameaças que provinham dessas áreas passaram a representar um tema de segurança pública nos Estados Unidos, como se deu com respeito ao problema das "maras" e do narcotráfico.

A evolução das relações México-EUA talvez represente a maior reversão de expectativa no contexto interamericano. Um horizonte de integração que parecia constituir a culminação de um entrelaçamento econômico e de um progressivo enquadramento do sistema político mexicano às regras do liberalismo se converteu numa humilhante "guetização" da nação asteca, cujos indicadores sociais tornaram-se cada vez mais distantes das previsões relativas ao impacto do Nafta do início dos anos 90.

No caso dos países sul-americanos, conservou-se uma relativa autonomia que oscila de acordo com as preferências de política externa de cada país. A identificação dessa região como uma esfera de influência contínua dos Estados Unidos para alguns, ou separada - operando como um sistema próprio -, para outros, foi a opção que orientou os relacionamentos bilaterais entre os EUA e a América do Sul (Russel $\&$ Calle, 2009).

\section{UM PROCESSO EM DOIS TEMPOS}

Quando se volta um pouco atrás observase que a deterioração das relações entre os EUA e a América do Sul alcançou seu pior momento na década de 80. Não obstante, os anos seguintes foram de recomposição com vistas à construção de uma agenda cooperativa nos campos econômico-comercial,

4 As"maras"são coletividades integradas principalmente por jovens centro-americanos que emigraram aos Estados Unidos procurando melhores condições de vida. Nos Estados Unidos, especialmente em Los Angeles, não encontraram a integração que desejavam e foram marginalizados. de segurança e de política internacional. O entusiasmo geral nos primeiros anos do pós-Guerra Fria, pelas instituições e regimes multilaterais, criou novas e positivas expectativas para a Organização dos Estados Americanos. Iniciativas como o lançamento do Compromisso de Santiago coma Democracia e a renovação do Sistema
Interamericano (1991) foram ilustrativas nessa direção. Os temas de destaque dos novos tempos da agenda hemisférica foram: comércio regional, defesa da democracia, proteção aos direitos humanos e segurança coletiva (Hirst, 1996).

As primeiras expectativas nos anos 90 foram, portanto, de que os tempos de estremecimento observados durante a segunda fase da Guerra Fria (1979-89) seriam substituídos por um relacionamento de inédito entendimento com a maioria das nações sulamericanas. A ilusão de que uma nova era de diálogo interamericano havia se instalado de forma definitiva esteve estreitamente associada ao predomínio de segmentos liberal-institucionalistas no comando da política externa norte-americana (Corrales \& Feinberg, 1999). Do lado sul-americanoa combinação dos processos de democratização e de liberalização econômica contribuiu para alimentar esse otimismo, ritualizado nas reuniões de cúpula presidenciais instituídas pela administração Clinton.

Ao longo dos anos 90 foram diversos os exemplos que revelavam a convergência entre ambas as partes na valorização dos regimes e instituições internacionais. Destacam-se iniciativas como o Protocolo de Kyoto (1997), a criação da Organização Mundial de Comércio (1995), o Protocolo de Ottawa sobre minas antipessoas (1992), o Regime Antimissilístico (1992) e a criação da Corte Criminal Internacional (1998). Nesse mesmo contexto, países como a Argentina e o Brasil cederam às pressões de Washington aderindo ao Tratado de Não Proliferação e coordenaram com Washington ações no âmbito regional, como a negociação de paz entre Equador e Peru e a contenção de forças antidemocráticas no Paraguai. A região parecia disposta, portanto, a endossar e ser parte de uma ordem hegemônica consensual institucionalizada.

Tornou-se flagrante, entretanto, o contraste entre o nível de coincidência das nações sul-americanas e os Estados Unidos na primeira e na segunda década do pósGuerra Fria. A partir do 11 de Setembro a utilização de políticas preventivas unilate- 
rais se converteu numa fonte de apreensão para os países sul-americanos, reacendendo sentimentos antiamericanos que haviam sido apenas timidamente expressos nos anos 90. Ao mesmo tempo se multiplicaram na América do Sul os focos de questionamento ao credo neoliberal, assumindo-se um distanciamento crítico à política de segurança dos Estados Unidos. Os desdobramentos da mudança de prioridade da política exterior de Washington após o 11 de Setembro somados à crise do modelo neoliberal revertem a tendência prévia, gerando para a América do Sul uma reação de prudente distanciamento frente à guerra contra o terrorismo liderada pela administração Bush. A opção pelo unilateralismo, que significou um progressivo desdém pelas instâncias coletivas, reduziu ainda mais o campo de concordância e coordenação entre os Estados Unidos e os países latino-americanos.

Ganha força a visão de que a nação imperial representava mais uma ameaça do que um fator de estabilidade para a região ${ }^{5}$. Dessa forma, o antiamericanismo sul-americano se propagou como uma resposta defensiva à apologia liberal do antiestatismo e tornou-se ainda mais vigoroso a partir das apreensões manifestadas pela administração Bush frente aos cenários políticos da região. Retomar-se-ia um embate ideológico semelhante ao que se observou nos anos 60 do século passado, quando a Guerra Fria projetou suas polarizações sobre a região. Para alguns autores esse comportamento foi interpretado como uma volta ao tempo da Guerra Fria (Lima, 2005; Tokatlian, 2005).

Surgia também o risco de que a preservação da margem de manobra das políticas sul-americanas fosse afetada pela ampliação da presença militar norte-americana na América do Sul, seja em função de suas vinculações com a Colômbia ou da montagem de Estabelecimentos Operativos Avançados. Observou-se a reativação do "fantasma" de ações intervencionistas na região a partir das apreensões manifestadas por parte do Comando Sul e do Departamento de Estado quanto aos desdobramentos de determinados processos locais.
As crises de governabilidade democrática foram associadas à noção de ameaça, o que inevitavelmente se traduzia na securitização das ações contempladas para superá-las. A percepção oficial dos EUA passou a ser de que a segurança regional enfrentava novos problemas gerados pelo desenvolvimento político negativo em países como Haiti, Bolívia, Venezuela e Equador. Menciona-se o surgimento de um "populismo radical”, identificado como uma "ameaça emergente", que coincidia com a crise de modelos democráticos na área (Hill, 2004).

Uma crescente desaprovação por parte dos países latino-americanos à política estratégica norte-americana logo ganhou espaço nos diferentes âmbitos da política regional e mundial. Foram muitos os sinais que explicitaram o distanciamento entre as partes: a recusa do México e do Chile em apoiar a invasão ao Iraque no Conselho de Segurança das Nações Unidas em 2003; os desentendimentos nas reuniões ministeriais de defesa; as motivações por trás da criação da Unasur; o tom afirmativo da política externa brasileira; o desenvolvimento de políticas de defesa em reação ao impacto do Plano Colômbia na área andino-amazônica; a polarização ideológica que passou a marcar lado a lado as relações ColômbiaVenezuela; a latino-americanização da agenda de trabalho da OEA; e a inclusão de Cuba no Grupo do Rio.

No campo econômico-comercial, a progressiva paralisação das negociações em torno da área de livre-comércio das Américas levou a uma agenda fragmentada de entendimentos sub-regionais. Ao mesmo tempo em que o governo norte-americano se mostrava disposto a aprofundar seu compromisso com o regionalismo, ele partia do pressuposto de que a Alca conduziria à dissolução de outros regimes de integração regional, como o Mercado Comum Centro-americano, a Comunidade Andina e o Mercosul. Adecisão dos Estados Unidos, anunciada em fevereiro de 2003, de fragmentar suas ofertas negociadoras mediante propostas diferenciadas quanto ao universo de produtos beneficiados por redu-
5 A oscilação entre as duas percepções é analisada por Buzan e Weaver (2003) 
ções tarifárias - uma para o Caribe (85\%) e outras para a América Central (64\%), para os países andinos $(68 \%)$ e para o Mercosul (50\%) - colocou em evidência o fim de um projeto interamericanode livre-comércio. A variedade de prazos de redução de produtos beneficiados levou a uma teia de negociações e pressões cujos principais resultados foram estimular a competição entre os países da região, aumentar o poder negociador norte-americano e enterrar a cláusula de nação mais favorecida no âmbito hemisférico. Ao lado do fracasso das negociações da Alca ganharam importância as negociações bilaterais de TLCs entre as quais se destacam os entendimentos alcançados com o Chile, Peru e a área centro-americana ${ }^{6}$.

\section{UM ELENCO DE}

\section{BILATERALISMOS}

Nesse mesmo contexto, passou-se a observar um padrão variado de vínculos bilaterais entre os países sul-americanos e os Estados Unidos. Três modelos podiam ser identificados: a) de alinhamento com tutelagem, como se dava com a Colômbia;

6 O TLC com o Chile foi assinado e referendado em 2005; oTLC com o Peru fo assinado em 2005 e ratificado pelo Peru em 2006 e pelos EUA em 2007; OTLC com a América Central foi assinado em 2004 e ratificado pelos EUA em 2006.

7 Desde 200 I a Usaid investiu 15 milhões de dólares e a NED 4 milhões de dólares para apoiar grupos de oposição ao regime de Hugo Chávez. Parte relevante desses recursos foi utilizada para apoiar a tentativa de golpe de Estado em abril de 2002 e a greve geral que perdurou por mais de dois meses em fins de 2002. Novosintentos deintervenção também receberam apoio norte-americano, como o plano consenso que apregoava a negativa no referendo de 2003 e as ações de desobediência civil em 2004.
Estado colombiano em troca da assistência militar.

Já a interação entre os governos norteamericano e venezuelano passou a reproduzir com notável fidelidade a típica confrontação ideológica da Guerra Fria. O predomínio de uma política confrontante vis-à-vis a administração norte-americana representou para a governo de Hugo Chávez um instrumento de coesão interna, especialmente após o intento de golpe de Estado em fins de 2002. Do lado de Washington, a utilização de recursos intervencionistas, como a CIA, a NED (National Endowment for Democracy) e o OTI (Office for Transition Initiatives), reanimou antigos métodos de desestabilização que se somaram à polarização da sociedade local ${ }^{7}$.

As relações com o Brasil não só mostraram um caminho bastante distinto do dos modelos mencionados, mas revelaram surpresas frente ao que vinha sendo esperado a partir de sua mudança de governo em 2003. Desde o seu início, o governo Lula esteve fortemente associado à ideia de mudança, o que, na política externa, trouxe como consequência a configuração de uma etapa afirmativa na interação com os Estados Unidos. De acordo com a visão oficial no Brasil, alcançou-se uma etapa de amadurecimento cujo resultado principal foi a configuração de um diálogo estratégico entre Brasília e Washington (Hirst, 2009b; Patriota, 2008).

Enquanto era certo que o Brasil havia contribuído de forma decisiva para obstruir - ao longo de dez anos - a negociação da Alca, sua atuação esteve sempre marcada por questionamentos substantivos mais do que por objeções ideológicas. O naufrágio da Alca na IV Reunião da Cúpula das Américas em 2005 adquiriu um sentido "liberador" que extrapolou a agenda negociadora em torno de uma área de livre-comércio hemisférica. A suspensão do processo negociador desvencilhou o Brasil de um projeto que, além de sempre haver merecido alto grau de desaprovação interna, impedia o governo Lula de confeccionar sua própria agenda com os Estados Unidos. Foi sintomático, nesse sentido, 
que no dia seguinte (literalmente) tivesse lugar a manifestação recíproca do interesse de construção de um agenda bilateral de amplo espectro. Em termos bilaterais, a ênfase pragmática passou a prevalecer no tratamento da agenda econômico-comercial, outorgando-se especial importância

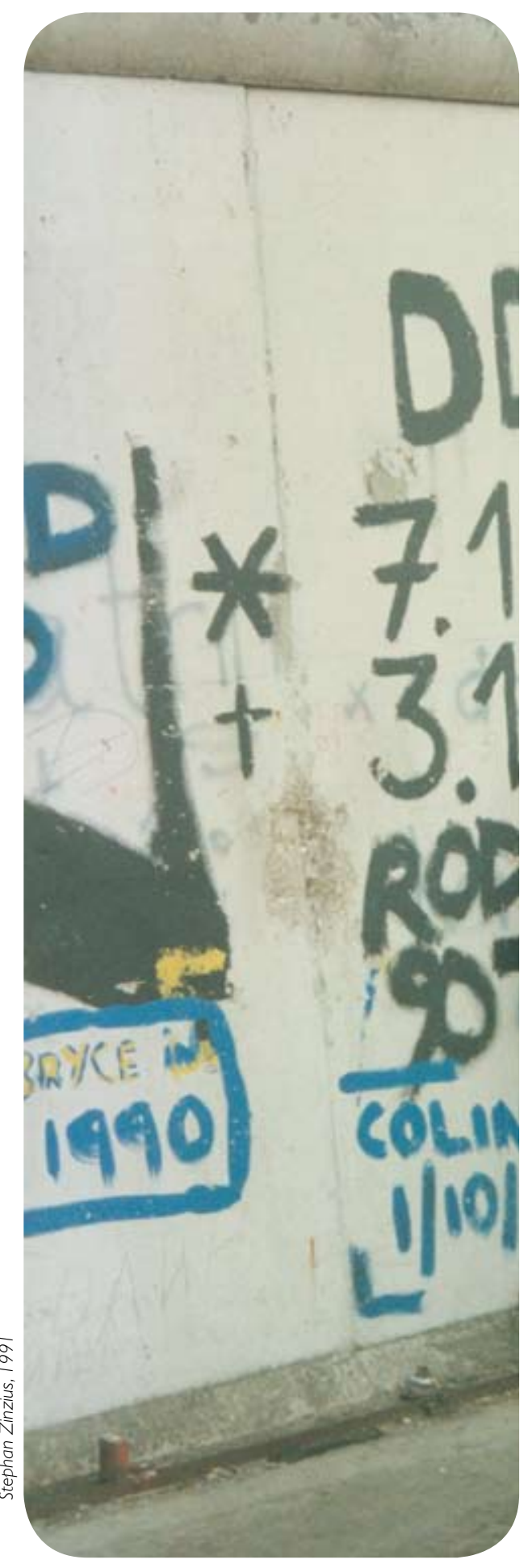

às coincidências com respeito a fontes de energia renováveis (especialmente na área de biocombustíveis).

Também nos terrenos político e de segurança o relacionamento Lula-Bush, depois de um período de distância, testemunhou uma sucessão de contatos positivos em níveis interministeriais e interpresidenciais. A etapa inicial de marcados desencontros foi substituída por relativa distensão; os principais pontos de discordância, se não desapareceram, deixaram de representar um empecilho para a identificação de áreas de entendimento. Washington, de seu lado, passou a reconhecer a necessidade de manter aberto um canal de comunicação com Brasília para lidar com a agenda política regional, particularmente em situações nas quais as instituições democráticas enfrentassem maiores riscos de continuidade - como se deu na Bolívia e na Venezuela. Um reconhecimento especial passou a ser reiterado nos encontros bilaterais de alto nível com respeito à intervenção brasileira no Haiti - valorizando-se a decisão do governo Lula de assumir o comando militar da Missão de Paz (Minustah) em 2003 (Hirst, 2009b). As premissas da política internacional do governo Lula não impediram que, para os Estados Unidos, essa presença adquirisse um sentido instrumental, considerando os custos políticos e militares de sua ação sobre-estendida no Afeganistão e no Iraque.

\section{PARA ALÉM DA AGENDA INTERAMERICANA}

Deve-se sublinhar que no pós-Guerra Fria, e especialmente a partir de 2001, a agenda internacional dos países latino-americanos, principalmente dos sul-americanos, não se limitou aos bons e/ou maus termos do relacionamento com os Estados Unidos. Observaram-se importantes movimentos em suas respectivas agendas regional e global; nem só de relações interamericanas viveram as agendas internacionais da região.

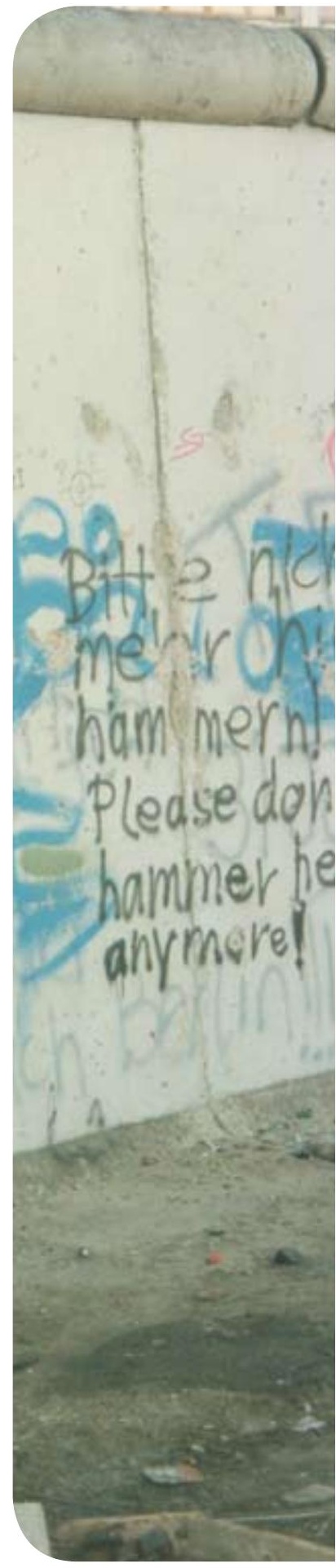


No plano intrarregional, houve uma notável reversão das expectativas presentes dos anos 90. No que diz respeito aos vínculos intrarregionais tornaram-se mais contundentes as tendências à fragmentação do que à integração; reduziu-se o ritmo dos processos associativos intergovernamentais, aprofundaram-se as peculiaridades das opções de governança democrática, e reforçaram-se as especificidades sub-regionais e nacionais. Ao lado da diferenciação entre o Norte e o Sul da região - condicionada pelo padrão de vinculação com os EUA -, o peso combinado da incidência de fatores histórico-culturais, da consolidação de processos político-institucionais pós-autoritários e de novas adversidades econômico-sociais tornou mais difícil a construção de projetos comunitários regionais e sub-regionais.
Também no âmbito político, foram crescentes as dificuldades políticas enfrentadas para a construção e/ou fortalecimento de instituições e regimes multilaterais na região. Por um lado, as inicativas reativadas ou de lançamento recente, como a CAN, o Mercosul e o Grupo do Rio, foram alvo de frustrações para assumirem papéis mais ativos na construção de uma cultura e de uma institucionalidade comunitária na região. Por outro, os projetos de instituição de agrupações inovadoras como a Comunidade Sul-Americana, agora renomeada de Unasur, perderam relevância frente às divisões internas que refletiam vazios ou diferenças de liderança, especialmente entre o Brasil e a Venezuela. Nesse mesmo sentido, a ideia de que a expansão dos recursos energéticos sul-americanos abriria caminho para um novo desenho estratégico

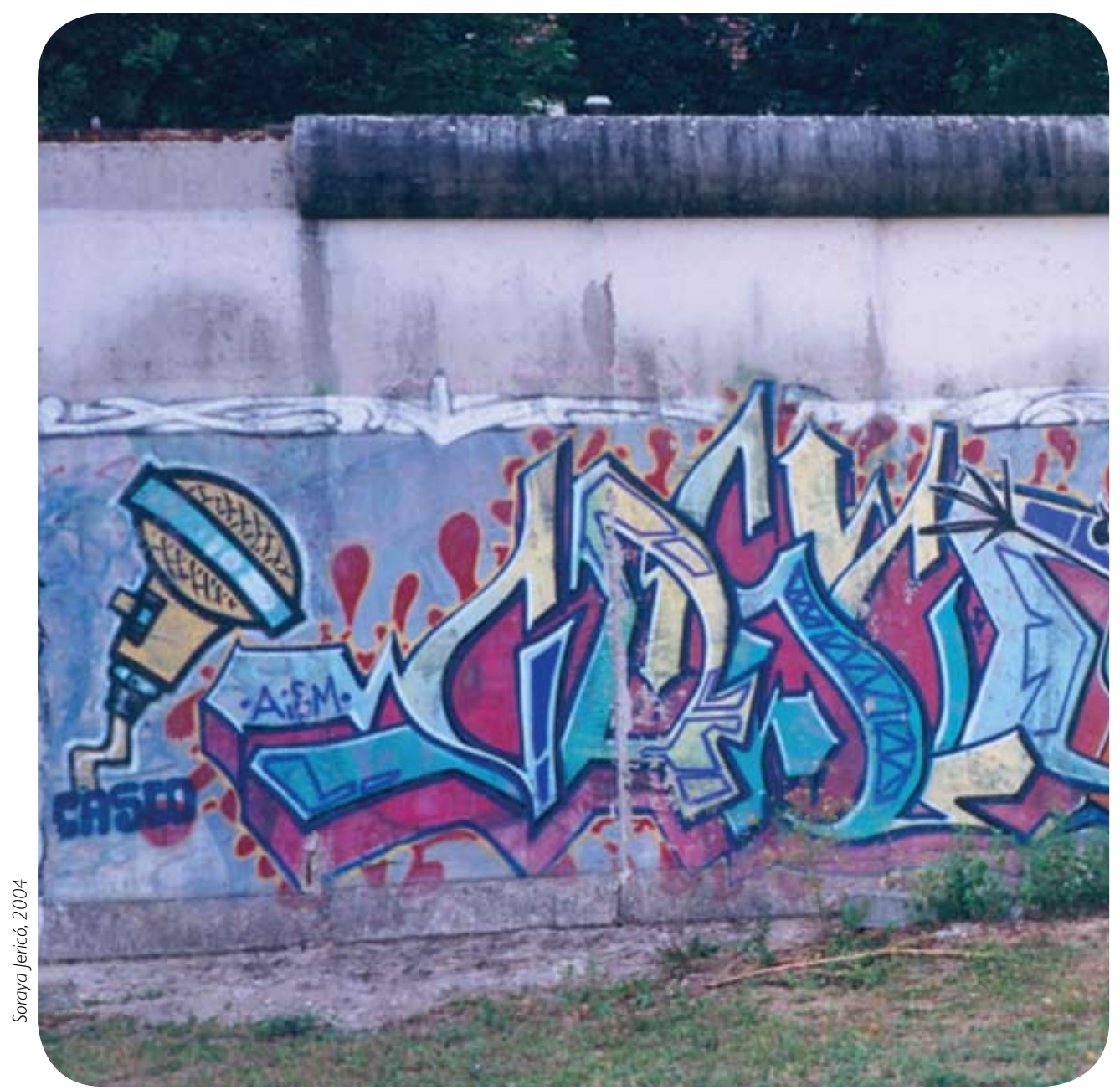


de integração regional terminou dando lugar a um cenário de disputas e diferenças estimuladas pelos interesses e necessidades de políticas individuais de crescimento e influência regional.

A agenda da segurança cooperativa, como uma prescrição norte-americana, foi arquivada a partir do 11 de Setembro, quando as novas prioridades estratégicas dos Estados Unidos resultaram na macrossecuritização de sua agenda hemisférica reduzindo a funcionalidade de regimes e instituições multilaterais. Diferentemente do que se esperava, ganharam novo ímpeto as políticas de defesa nacionais acompanhadas pelo aumento dos orçamentos militares e a reativação de algumas rivalidades interestatais.

No lugar de uma divisão entre dois subsistemas de segurança Andes/Cone Sul, a América do Sul se transformou num complexo emaranhado de tensões bilaterais, de redes de operações transnacionais de delito e de respostas fragmentadas às pressões estratégicas dos Estados Unidos (Russell \& Tokatlian, 2008). Nesse contexto, a guerra na Colômbia, ao invés de representar um foco de irradiação de insegurança regional gerador de políticas comuns para a sua contenção, converteu-se num processo encapsulado de conflito intraestatal, de acordo com as descrições do retrato-falado das ameaças terroristas definidas desde Washington e manejado conjuntamente pela Colômbia e os Estados Unidos. Esse encapsulamento não impediu que se alastrasse uma teia de conexões transfronteiriças entre os grupos narcoguerrilheiros colombianos e as organizações de delito operantes em diferentes países sul-americanos.

Tomando-se o argumento de que o fim da Guerra Fria propiciava maior liberdade para que as regiões ampliassem a responsabilidade sobre suas respectivas agendas de segurança concluiríamos que a América do Sul fez um uso modesto dessa oportunidade em termos coletivos (Buzan, 2003, p. 18). Outrossim, as dificuldades econômicas e de gestão encaradas por seus estados para assegurar eficientes políticas regionais de segurança e defesa agravaram-se frente ao impacto - observado mundialmente - da vinculação entre a dimensão internacional do crime e a porosidade dos mecanismos de controle da circulação de bens, serviços, dinheiro e pessoas estimulada pela globalização (Hurrell, 1998; Tokatlian, 2000; Mittelman \& Johnston, 1999). Os primeiros passos para reverter essa tendência foram dados com a criação recente do Conselho de Defesa sul-americano.

Deve-se destacar que os modestos resultados no terreno da construção comunitária foram acompanhados, entretanto, por importantes transformações na articulação da região com a agenda global. Não obstante sua marginalidade estratégica e os limitados resultados de suas iniciativas institucionais regionais, a América do Sul ampliou notavelmente sua presença nas ações multilaterais vinculadas à preservação da paz e à

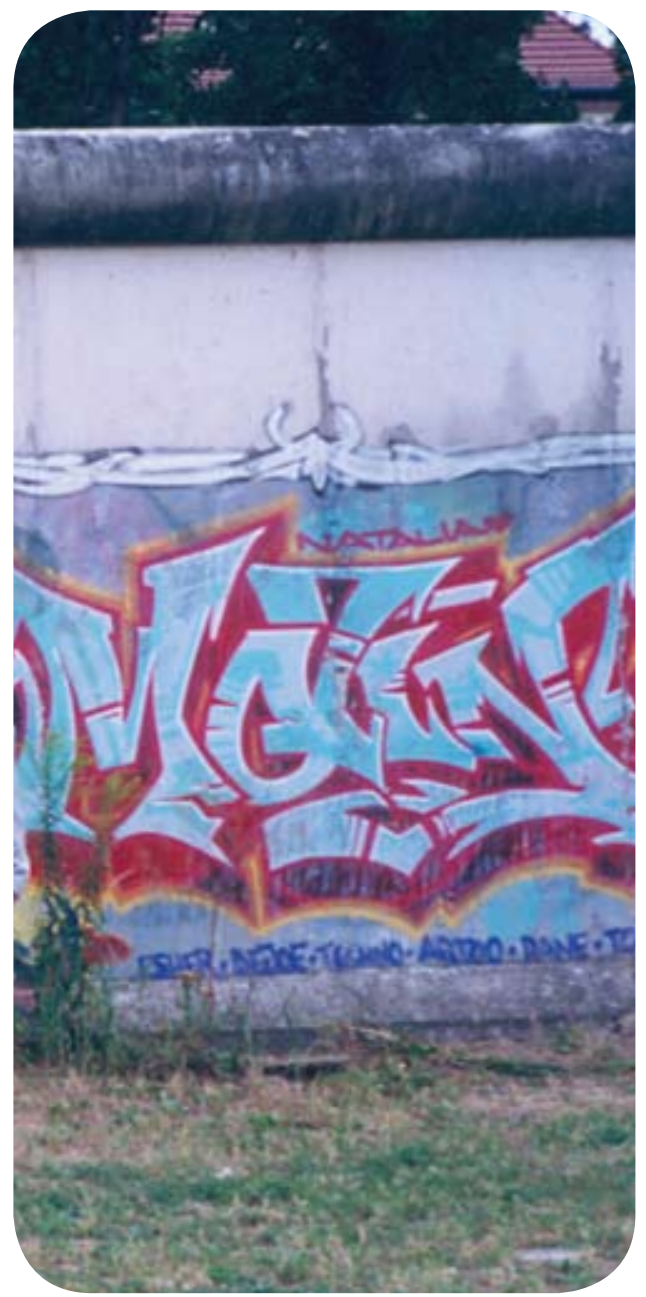


cooperação internacional. Atualmente os países sul-americanos oferecem mais intervenção do que recebem ao mesmo tempo que assumem um novo papel na Cooperação Sul-Sul. A Ásia e a África também são importantes ofertantes de contingentes para as operações de paz, mas correspondem às áreas nas quais essas missões se fazem mais presentes. No contexto sul-americano, os países de maior desenvolvimento relativo e/ou estabilidade institucional - Argentina, Brasile Chile-parecem decididos a manter e expandir sua atuação em processos de reconstrução pós-bélica aprovados e instituídos pelo Conselho de Segurança das Nações Unidas.

Também ganhou relevância a presença de países latino-americanos em espaços multilaterais dedicados a temas econômicos globais, mencionando-se o G20 - no contexto dos esforços pela conclusão da Rodada Doha - e o G24 - convocado com o propósito de buscar uma saída consensual para a crise financeira internacional, deflagrada desde fins de 2006. Em ambos os casos a atuação do Brasil, como um poder emergente, adquiriu especial visibilidade política em função de seu empenho por assumir um papel mediador no diálogo entre as nações industrializadas e os países do Sul (Burges, 2008).

Novos horizontes também emergiram na articulação da região com a agenda internacional da cooperação internacional. É na América Latina que se observa atualmente o maior percentual de países de renda média (PRMs) (79\%) no cenário internacional (o que não impede que essa região se destaque por apresentar os maiores índices de desigualdade no mapa social mundial). Ao mesmo tempo, os desafios gerados pelo contexto da crise econômica global aumentam a pressão sobre os países receptores de cooperação internacional, especialmente aqueles que atuam também como doadores, como ocorre com Argentina, Colômbia, Chile e Brasil. No âmbito sul-americano, o fato de o Brasil assumir um papel cada vez mais relevante no aprofundamento e na inovação da Cooperação Sul-Sul (CSS) implica, para seus vizinhos, um conjunto

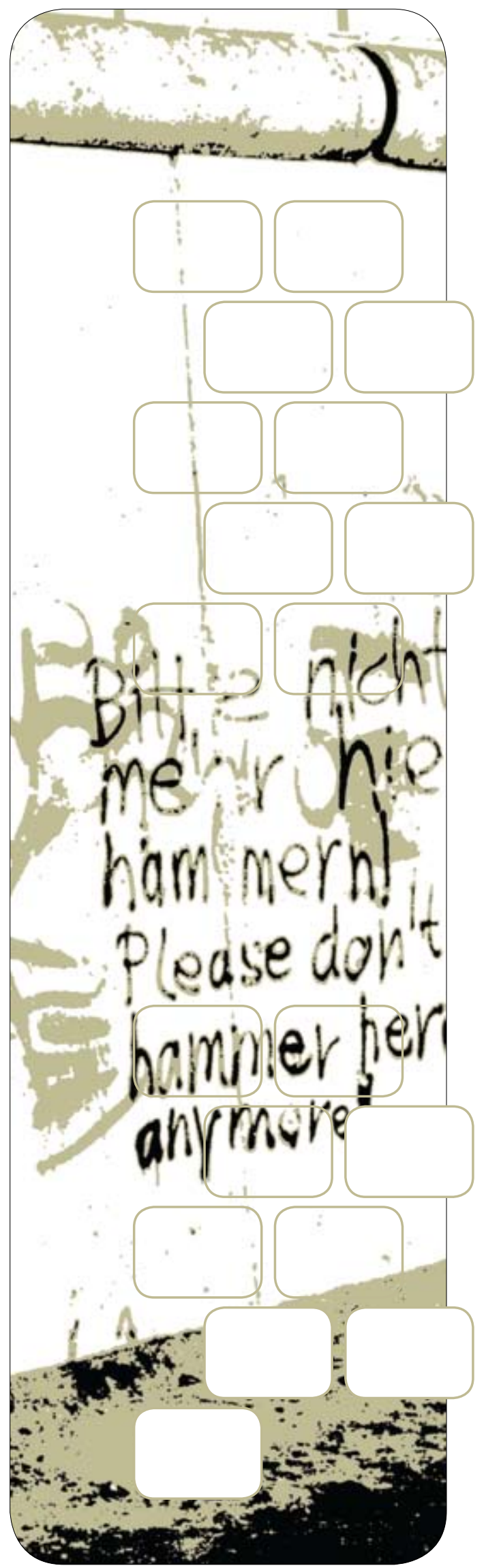


de possibilidades de horizontalidade que poderiam se transformar em processos de aprendizagem e de oferta coordenada (Hirst \& Lima, s.d.). Deve-se ter presente que para a política externa brasileira esse desempenho está associadoàs iniciativas políticas de coordenação com outros poderes regionais, mencionando a Índia e a África do Sul a partir da criação do Ibas em 2003.

Deve-se ter presente, também, que a CSS na América do Sul já não se limita à cooperação técnica para o desenvolvimento. Atualmente, esta pode implicar tanto um elenco de possibilidades de assistência técnica, a transferência de recursos líquidos - como estão previstos no caso do Fundo Ibas (Índia, Brasil e África do Sul) para projetos de cooperação no Haiti e na Guiné Bissau e do Focem (Fundo de Convergência Econômica do Mercosul), destinado a programas de desenvolvimento no Paraguai e no Uruguai -, como iniciativas de apoio institucional em áreas de governabilidade democrática, o que lhe gera um atributo diferenciado. A convergência entre as trajetórias em políticas de desenvolvimento, democratização e CSS dos países sul-americanos lhes confere um papel político e operativo na agenda global de assistência ao desenvolvimento e à estabilidade política. Em particular, Argentina, Brasil e Chile (ABC) vêm contribuindo para o fomento de novas agendas de CSS que preveem a articulação mais estreita entre a cooperação político-institucional e a promoção do desenvolvimento.

Finalmente, deve-se ter presente a exposição da região às transformações do mercado internacional, as novas possibilidades de vinculações comerciais e de fontes de investimento externo. A abertura das economias latino-americanas favoreceu uma porosidade estimulada pelo dinamismo das economias emergentes - especialmente a China e a Índia -, além da diversificação de laços com as economias industrializadas. Como em toda parte do mundo, também na América Latina os vínculos entre as dimensões regional e internacional adquiriram novo significado para as realidades locais a partir da globalização.

\section{AS INCERTEZAS DO PÓS-PÓS}

Inegavelmente, com o fim da administração Bush, virou-se a página do cenário de polarizações ideológicas brevemente narrado. Os novos ventos produzidos pela chegada de Obama à Casa Branca sopraram em todo o planeta, incluindo a América Latina. O imediato abandono da política estratégica de seu predecessor gerou expectativas - possivelmente sobredimensionadas - de mudanças e reposicionamentos em todos os temas mundiais. No que tange à política latino-americana, apesar de não haver urgências, como na Ásia Central e Oriente Médio, transmitiu-se uma mensagem que misturava mea-culpa com necessidade de aggiornamento. Não está claro entretanto qual a capacidade da nova administração de ajustar-se e vincular-se positivamente à região, especialmente quando se tem em conta a nova configuração da inserção internacional desta última.

Durante a $5^{\text {a }}$ Cúpula das Américas em Trinidad e Tobago (abril de 2009), conheceu-se um discurso que revelou um esforço de atualização sobre a região articulado ao que agora se chama de "poder astuto" (smart power) no novo léxico da Casa Branca. De fato, buscou-se somar a região ao sentido de mudança e à enfática defesa de instituições e valores democráticos, sem promover entretanto alterações mais relevantes no status da região no conjunto de prioridades globais. No plano simbólico, que vem sendo uma dimensão especialmente importante da nova política internacional da Casa Branca, a reunião do novo mandatário americano com os seus pares da Unasur correspondeu a um divisor de águas para a região. Pela primeira vez se reconhecia a representatividade de uma organização regional que não incluía os EUA como membro (vale recordar que, durante toda a crise centro-americana, Washington jamais admitiu o poder de interlocução do Grupo de Contadora ou de Apoio).

Já na assembléia da OEA (maio de 2009) novos passos foram dados nessa mesma direção quando se aprovou a Resolução 
2.438, que prevê o início de um processo de revogação da exclusão de Cuba desse organismo. De fato, colocar esse tema sobre a mesa e dar começo à reincorporação desse país à comunidade interamericana sinaliza o fim tardio da Guerra Fria na política latino-americana dos EUA. Ao mesmo tempo, cria-se espaço para que outros países da área - especialmente o Brasil possam atuar como mediadores do degelo entre Washington e Havana, favorecendo a substituição de um enfoque ideológico por um tratamento político do tema. Abriu-se o horizonte para que a defesa enfática de valores democráticos passe a estar desvinculada de uma diplomacia coercitiva e do uso de sanções como método de pressão política, o que significa o abandono das práticas legitimadas nos velhos tempos da Guerra Fria.

Como já foi comentado, a crise de liderança de Washington nos anos recentes na região, acompanhada pela falta de interesse e energia política para lidar com "turbulências periféricas", contribuiu para que o Brasil desse passos largos para consolidar sua condição de poder regional (Lima, 2008). A política sul-americana do governo Lula, ao lado da nova presença econômica do país em toda a vizinhança, colabora para que essa condição associe positivamente aspirações próprias a necessidades que dificilmente poderiam ser atendidas pelos EUA. Naturalmente, as condições desse lugar terão que ser renegociadas com o novo mandatário norte-americano no contexto dos compromissos de mudança assumidos desde o período de campanha presidencial.

Após as primeira manifestações, entretanto, tornou-se menos claro se a administração Obama empreenderá um caminho inovador tout court, ou se procurará preservar algumas fileiras de tijolos do Muro de Berlim no âmbito interamericano - mesmo após vinte anos de sua derrubada na política mundial. As resistências ao levantamento do embargo a Cuba, o desconforto com a gestão do atual secretário-geral da OEA e as ambiguidades frente ao golpe de Estado em Honduras são indicações de que a biruta poderia se mover em qualquer direção. Uma reversão de expectativas quanto a "novos tempos" da política latino-americana dos Estados Unidos parece ajustar-se à percepção de que finalmente continuidades poderão se sobrepor ao impulso de mudanças maiores no caso da agenda interamericana (Joyner, 2009). Nesse caso caberá à América Latina, e especialmente à América do Sul, consolidar por sua conta a condição de ex-área de influência norte-americana. Naturalmente, o papel do Brasil não deveria ser menor nesse empenho.

\section{BIBLIOGRAFIA}

BURGES, Sean W. "Consensual Hegemony: Theorizing Brazilian Foreign Policy After the Cold War", in International Relations. vol. 22, n. 1, March/2008, pp. 65-84.

BUZAN, Barry. Regions and Power: the Structure of International Security. Cambridge, Cambridge University Press, 2003.

BUZAN, Barry \& WEAVER, Ole. "South América: an Under-conflictual Anomaly?", in Regions and

Powers: the Structure of International Security. Cambridge, Cambridge University Press, 2003. CORRALES, Javier \& FEINBERG, Richard E. "Regimes of Cooperation in the Western Hemisphere: Power, Interests, and Intellectual Traditions", in International Studies Quarterly, vol. 43, 1999, pp. 1-36. 
HILL, General James. Testimony of before the House Armed Service Committee. United States Army Commander, United States Southern Command. United States House of Representatives, 24/ março/2004.

HIRST, Monica \& LIMA, Maria Regina Soares de. "Brazil as an Intermediate State and Regional Power: Action, Choice and Responsibilities", in International Affairs, vol. 82, n. 1, s.d., pp. 21-4.

HIRST, Monica. Democracia, Seguridad e Integración. América Latina en un Mundo en Transición. Buenos Aires, Grupo Editorial Norma, 1996.

. "Seguridad Regional en las Américas", in Friederich-Erbert-Stiftung (Fescol). La Seguridad Regional en las Américas. Enfoques Críticos y Conceptos Alternativos. Bogotá, Wolf Grabendorff editor, 2003.

. "La Intervención Sudamericana en Haiti", in Monica Hirst (comp.). Crisis de Estado e Intervención Internacional. Buenos Aires, Edhasa, 2009a, pp. 29-72.

Brasil-Estados Unidos: Desencontros e Afinidades. Rio de Janeiro, Editora FGV, 2009b.

HURRELL, Andrew. "Security in Latin América", in International Affairs, vol. 74, n. 3, 1998.

JOYNER, James. "Bush's Third Term", in The National Interest Online, 22/7/2009.

KUNDERA, Milan. Un Encuentro. Buenos Aires, Tusquets, 2009.

LIMA, Maria Regina Soares de."Guerra Fria, de Volta à América do Sul?", in Observatório Político SulAmericano. Instituto Universitário de Pesquisas do Rio de Janeiro luperj/Ucam, 2005. . "Liderazgo Regional en América del Sur: ¿Tiene Brasil un Papel a Jugar?", in Ricardo Lagos. América Latina: ¿Integración o Fragmentación?. Buenos Aires, Edhasa, 2008.

MITTELMAN, James H. \& JOHNSTON, Robert. "Globalization of Organized Crime, the Courtesan State, and the Corruption of Civil Society", in Global Governance, vol. 5, n. 1, jan./mar./1999.

PATRIOTA, Antonio de Aguiar. "O Brasil e a Política Externa dos EUA", in Política Externa, vol. 17, n. 1, jun.-jul.-ago./2008.

PRZEWORSKI, Adam. Democracy and the Market. Cambridge, Cambridge University Press, 1991. RUSSEL, Roberto; TOKATLIAN, Juan Gabriel. "Resistencia y Cooperación: Opciones Estratégicas de América Latina Frente a Estados Unidos", in Ricardo Lagos. América Latina: ¿Integración o Fragmentación?. Buenos Aires, Edhasa, 2008.

RUSSEL, Roberto; CALLE, Fabián. "La 'Periferia Turbulenta' como Factor de la Expansión de los Intereses de Seguridad de Estados Unidos en América Latina", in Monica Hirst (comp.). Crisis de Estado e Intervención Internacional. Buenos Aires, Edhasa, 2009.

SANJUÁN, Ana Maria. "América Latina y el Bolivarianismo del Siglo XXI, Alcances y Desafíos de la Política Venezolana Hacia la Región", in Ricardo Lagos. América Latina: ¿Integración o Fragmentación?, Buenos Aires, Edhasa, 2008.

SAULL, Richard. "El Lugar del Sur Global en la Conceptualización de la Guerra Fría: Desarrollo Capitalista, Revolución Social y Conflicto Geopolítico", in Daniela Spenser (coord.). Espejos de la Guerra Fría. México, América Central y el Caribe. México, Ciesas, 2004.

SKIDELSKY, Robert. The World After Communism. London, Papermac, 1995.

SNYDER, Jack. Myths of Empire: Domestic Politics and International Ambition. Ithaca, Cornell University Press, 1991.

TOKATLIAN, Juan. Globalización, Narcotráfico y Violencia: Siete Ensayos sobre Colombia. Buenos Aires, Norma, 2000.

. "El Regreso de la Guerra Fría", in La Nación. 10 de abril, 2005. 